\title{
THE SPECIAL ISSUE ON ATTACHMENT: OVERREACHING THEORY AND DATA
}

\author{
Pamela S. Ludolph
}

\begin{abstract}
The Family Court Review Special Issue edited by McIntosh focused on the views of traditional attachment theorists, neglecting to interview more progressive thinkers or put many thought-provoking questions to the traditionalists. The advances in attachment research in the last half century were little acknowledged. Among the unexplored research findings were the discovery that early attachment status can change, often as a result of negative life events; that maternal deprivation and other early losses are recoverable; and that infants do not require one primary caregiver to thrive. The notion that young children should not have overnight stays with their fathers was presented as fact, when little convincing research exists on the question.
\end{abstract}

Key Points for Family Court Community:

- The Family Court Review Special Issue presented the views of traditional attachment theorists.

- More contemporary views of attachment were not presented in a balanced way.

- Among the ideas supported by current attachment research that were insufficiently addressed are:

Early attachment does not uniquely determine later functioning.

Early losses are generally recoverable.

Infants and young children form multiple attachments and generally are attached to both their mothers and fathers.

Current research is sparse and provides no convincing support for the idea that young children should have little or no overnight time with their fathers.

Keywords: attachment; young children; multiple attachments; overnight care; shared time; divorce; child custody

The July 2011 Special Issue of Family Court Review focuses on attachment theory, a rich and significant body of knowledge that is more than worthy of careful attention. The central idea of attachment theory, that early sensitive care is of great importance to children, has by now been well supported, and its implications for divorce are certainly of interest. The Special Issue's guest editor whetted the reader's appetite by promising a kind of "attachment reconnaissance mission" (McIntosh, 2011, p. 219), with challenging questions and an engaging style. The guest editor settled on a format for the issue that presented eight interviews with well-known attachment theorists, adding two conventional journal articles, and an introduction that both describes her thinking in putting the Special Issue together and summarizes the views of the interviewees.

This comment addresses a number of problems I found with the conceptualization and conduct of the interviews. I also note some perplexing ways the interviews and the summary of the Special Issue misconstrue and overreach both the literature on attachment and the remarks of the interviewees. I will have little to say about the scholarly papers in the volume. And, although the summary states briefly that the primary caregiver need not be the mother, the interviewees tended to talk about mothers as the primary caregivers and fathers as the visiting parents. I will generally adopt that convention.

\section{THE CONCEPTUALIZATION AND CONDUCT OF THE INTERVIEWS}

The introduction helpfully provides the selection criteria for the interviewees: they were to be "experts who had published original attachment research (conducted in the Bowlby/Ainsworth tradition) in high-ranking international journals" (McIntosh, 2011, p. 421). Interviewees were to have had

Correspondence: pludolph@umich.edu 
"exposure to divorce-related issues, but for whom divorce was not their chief line of publication" (McIntosh, 2011, p. 421). The group selected was undoubtedly distinguished, and more than met the established criteria. One is struck, however, not by who was included in the group, but who was omitted. Michael Lamb was not included, despite his international reputation as a distinguished scholar, having published attachment research in excellent journals since the 1970s. Ross Thompson is similarly distinguished and similarly not interviewed, having done much scholarly work in the field of attachment. Both of these authors have written on divorce; for both, it is not their principal area of study. There are more. Michael Rutter, an attachment theorist and one of the deans of child psychiatry worldwide, is cited throughout the issue. Marinus van IJzendoorn, one of the most enduring and prolific researchers in the field, has conducted all manner of research for decades, including studies in areas relevant to divorce, like father-infant attachment. Mary Dozier has done extensive study on the ways that foster children meet the challenges of forming attachments after lives of loss and adversity, certainly an area with conceptual ties to divorce. All of these remarkable scholars were sadly not interviewed. In constructing a Special Issue without their voices or those of others like them, the guest editor limited the reader's exposure to the ideas of a moderating wing of attachment theory, those who applaud what is good about the theory, but who critically examine ideas that are more questionable.

Also omitted, not only from the panel of interviewees but from the Special Issue overall, is mention of respected scholars who have contributed work on infants and very young children of divorce and who do not represent themselves primarily as attachment theorists. Thus, no paper or interview of the 11 articles in the Special Issue cites Marsha Pruett on young children and divorce, despite the several papers she has written, including one of the few on infants and overnight parenting time, a major focus of the issue (Pruett, Ebling, \& Insabella, 2004). Joan Kelly, an acknowledged leader in research on the children of divorce, is cited only once, in the scholarly paper by Main, Hesse, \& Hesse (2011). In the last decade, these authors and others like them have been undeniably persuasive to social scientists and courts. Their omission from the panel of interviewees may be understandable, in that attachment was the focus of the Special Issue; their virtual omission from the reference lists of the entire issue is not.

There is also the matter of the kind of questions chosen for interviewees who, though they were a conceptually narrow group, represented a treasure trove of knowledge that could have been mined. Apt questions were often asked of course, but, again, it is the omissions that are of concern. For the most part, the interviewees were not asked about the nature of their research and clinical experience with divorce, questions that would have grounded the naïve reader in the context within which the scholar answered, and helped the reader weigh the sufficiency of the response. Controversial or difficult questions were largely avoided. An instance here is the questioning of Solomon and George about their research on overnight care. Their studies (Solomon and George, 1999a; 1999b) have proved beyond controversial in the divorce literature, given the authors' acknowledgment of methodological difficulties in their work, and the fact that there are but a handful of studies of overnight care in the literature altogether. In the Special Issue, Solomon was simply asked if she was "comfortable" with her conclusions that overnights with fathers were stressful to the mother-child relationship, to which she responded, "I am" (George, Solomon, \& McIntosh, p. 522). The reader is not well-served, and even a little frustrated, when no follow-up question is posed.

A related concern is the issue's easy acceptance of unelaborated and ultimately incomplete answers, or even answers that contradict those of other interviewees. The summary statements in the introduction sometimes seem to omit the opinions of interviewees whose ideas varied from the viewpoint of traditional attachment theory. The guest editor fairly notes that agreement on most points was to be expected given the theoretical orientation of those selected. It would then follow that variance from the expected views would be of some interest and at least merit mention in the summary. An example of such selective reporting is found in the context of the issue of neurological differences between men and women. Alan Schore notes, controversially, that the female brain is "specifically equipped for the largely nonverbal, affiliative, nurturant aspects of attachment formation with an infant" (Schore \& McIntosh, 2011, p. 424). This opinion is duly noted in the summary, but there is no mention of the countervailing opinion of the other neuroscientist interviewed, Daniel Siegel, who finds attachment "gender neutral" (Siegel \& McIntosh, p. 519). Charles Zeanah, another 
one of the interviewees, and a physician, also recently offered that there is presently little understanding of the neurology underlying attachment processes (Zeanah \& Smyke, 2008); he is not asked about the issue at all. Thus, an interesting and likely enlightening discussion is sidestepped.

\section{IS ATTACHMENT STATUS UNIQUELY PREDICTIVE OF LATER FUNCTIONING?}

A question posed in the introduction to the Special Issue is one of critical importance: "How valid and all-encompassing is attachment research applied to the divorce population?" (McIntosh, 2011, p. 420). There are various and compelling answers possible to this question. Unfortunately, most of them remain unexplored in the issue. I will address a few, with particular reference to opinions of the interviewees that may have been misunderstood or unstated in the Special Issue or its summary (see Ludolph \& Dale, 2012, for a more comprehensive review). There is some emphasis on the summary, which is presented in tabular form, presumably so that a reader could come away with a quick précis of the views in the interviews, in some cases perhaps without thoroughly reading the papers. Thus, it is of particular concern if the summary is incomplete or inaccurate.

The first issue, the impact of early attachment status on later functioning, was explored with two of the interviewees at some length, but not mentioned in the summary. There is no doubt that attachment status varies among young children, and that adverse early childhood circumstances influence assessed attachment status, as do more favorable ones. Sensitive parenting is of particular importance to early attachment status. What is becoming clearer of late is the relationship of early attachment to long-term attachment status and functioning. These data are now available because of the work of those theorists who have followed individuals for decades, such that they can give us results from outcome data on adolescents and young adults whom they first studied as infants. Two of the principal authors of the few long-term attachment studies that exist are Waters and Sroufe, interviewees of the Special Issue. Both of them are strong believers in the importance of early attachment and traditional attachment theory and say as much in their interviews. Both of them were among those whose long-term studies showed a relationship between early attachment and adult outcome, at least in part. Yet, both are careful not to over-construe the unique contribution of early attachment, realizing that there are as many long-term studies that show continuity of attachment status as there are those that do not (Thompson, 2006).

Both Sroufe (Sroufe \& McIntosh, 2011) and Waters (Waters \& McIntosh, 2011) are in firm agreement that early attachment alone is not determinative of adult functioning and that attachment status is not necessarily stable over time. A securely attached toddler may grow up to face mental illness; an insecurely attached child may later flourish. In his own report on 50 middle class young adults whom he had followed for 20 years, Waters found stability of attachment status over time, but also concluded, "throughout childhood, attachment representations remain open to revision in light of real experiences" (p. 687). He repeats this message clearly in his interview in the Special Issue: "Infant attachment is a starting point. Every journey has to start somewhere. But it is not the end of the story" (Waters and McIntosh, 2011, p. 477). Sroufe makes similar points in his description of his study of 180 high-risk families over 30 years. His group has reported some data reflecting long-term continuity of attachment and behavior, and some data where no continuity was seen. Sroufe notes, "it is the cumulative history (as well as current challenges and supports), and not early attachments alone that account for any observed outcome" (Sroufe, 2005, p. 362). Indeed, some variables, for instance adult mental illness, were more related to environmental factors subsequent to early childhood than to early attachment (Sroufe, Egelund, Carlson, \& Collins, 2005). In his interview, Sroufe is clear: "early attachment is not destiny" (Sroufe \& McIntosh, 2011, p. 465). Both Waters and Sroufe speak of life events, positive and negative, that can modify attachment status, including: social support, changes in parenting quality, changes in economic status, changes in employment, problems with the law, substance abuse, divorce, loss of a parent, serious illness of a family member, parental mental illness, and physical and sexual abuse of the child (Waters, Merrick, Treboux, Crowell, \& Albersheim, 2000; Sroufe, 2005). 
If negative life events are as important, or sometimes more important, to adult outcomes than early attachment status, does not this bear mention in the summary? Do the data justify always ranking attachment over other factors in divorce, when children are very young, as most contributors to the Special Issue seem to do? These are, of course, open questions, but a balanced view would require that all sides of the issue be examined.

\section{THE CONCEPT OF LOSS IN ATTACHMENT THEORY AND DIVORCE}

A confusing aspect of attachment theory is its imperfect and sometimes overbroad definition of separation and loss, a subject to which John Bowlby (Bowlby, 1973, 1980), the architect of attachment theory, devoted a good deal of his writing. Obviously, this topic has much bearing for families of divorce. Bowlby's focus on infantile relationships, innovative as it was in the middle of the twentieth century, led to an early interest in what he termed "maternal deprivation" (Bowlby, 1951). Based primarily on his study of institutionalized children, he postulated that a child's loss of the mother early in life could lead to great and enduring psychological harm. Robertson was an early collaborator of Bowlby's who soon followed up on this idea, studying toddlers who were separated from their mothers for periods of days or a couple of weeks. Robertson recorded in print and in film the evident sadness, protest, and, later, emotional detachment of the babies at these separations. Bowlby was quite taken with these data as confirmation of his theory. Writing nearly 20 years later, with his wife and coauthor, Robertson was much less certain, "[Bowlby] has generalized Robertson's concept of protest, despair, and denial beyond the context from which it was derived ... Our findings do not support Bowlby's generalization about the responses of young children to loss of the mother per se" (Robertson \& Robertson, 1971, p. 313). The Robertsons also noted that these children did not have the seriously maladaptive characteristics of other children they had studied who experienced long-term institutional care. They wrote that the difference between the children they observed in shorter term separations and those they saw in institutions was "qualitative and not merely of degree. All were able to use the substitute for the absent mother" (Robertson \& Robertson, 1971, p. 312).

Like Robertson, Rutter took on the study of loss, maternal deprivation, and early childhood institutionalization very early in the history of attachment theory (Rutter, 1971). What he has learned, after a lifetime of research, turns out to be quite measured and sensible. Rutter determined that the context of the loss is very significant, as Waters points out in his interview (Waters \& McIntosh, 2011). As the number of early stressors increase, so does the short and long-term damage to the children. Main, Hesse and Hesse (2011) make this point well in their article in the Special Issue, emphasizing that Rutter did not think that separations were determinative of later development, and noting that this became Bowlby's view as well (Bowlby, 1988). Rutter and his colleagues also found, however, that the toll of years of early abusive and neglectful care turns out to be often marked and unrecoverable, even if the child is adopted into a loving home (Rutter \& Sonuga-Barke, 2010).

These distinctions in regard to early loss bear on aspects of the interviews. The interviews (and the introduction to the Special Issue) pose hypothetical situations and questions that presume infant separations from either or both parents of weeks or months, or custodial arrangements where young children must frequently spend hours and hours travelling very long distances between their parents. Some such separations might well mimic the situation of the toddlers seen by the Robertsons, who were well cared for by friends or foster parents, but missed their absent mothers. Of course, such things can happen to infants of divorce on occasion. There are, for instance, quandaries and uneasy resolutions when the parent of a young child relocates a long distance from the other parent (Austin, Ludolph, \& Gould, 2011). For the most part, however, overnight time for very young children is distributed by well-intended judges and parents such that children are not without either parent for very long. Kelly and Lamb (2000) well describe a good parenting plan for the very young: "The ideal situation is one in which infants and toddlers have opportunities to interact with both parents every day or every other day in a variety of functional contexts (feeding, play, discipline, basic care, limit setting, 
putting to bed, etc.)" (p. 304). In the view of those authors, and this one, the best parenting plan for young children whose parents communicate and relate reasonably well would logically incorporate overnight care.

It should be carefully noted, however, that when those of us who do this work contemplate parenting plans for infants and toddlers, we are almost never planning for children who spent their first years in Romanian orphanages or in other situations of unremitting abuse and neglect. One of the interviewees, Charles Zeanah, has been among those who have studied institutionalized children with Rutter, and described the children as having severe attachment and behavior disorders (Zeanah, Smyke, Koga, \& Carlson, 2005). Zeanah would never confuse one of these children with a typical child of divorce who had been separated for a few days too long from his mother. As Robertson said, the difference is unmistakable.

Indeed, unlike traditionalists who presume that mothers take care of babies all day long, mental health professionals who assist the court are often planning for young children of two working parents, who spend much of each day in the care of babysitters and child care centers. Little mention is made in the Special Issue of the obvious contradiction inherent in giving the mother necessary latitude to put her baby in child care where the child invariably naps in the day, while forbidding overnight care with the father, who would have the child sleep at his house. Indeed, sometimes the child is permitted to nap at her father's house by day but not sleep at night. It is of some interest that Sagi and his colleagues (Sagi, Koren-Karie, Gini, Ziv, \& Joels, 2002) have found that infants who are cared for by relatives have significantly enhanced attachment to their mothers, when compared to infants in the fulltime care of their mothers. This paradigm makes sense for many infants of divorce, given the stresses and strains of fulltime work while caring for an infant as a single parent. Significant relief from childcare during the day and at night might reasonably lead to a refreshed mother, ready and eager to provide the secure base needed for the child's social and emotional development. And surely the father would be a good choice for a relative caregiver.

This brings me to a last point about the odd remarks of some of the interviewees on the infant's experience of night and dark. The guest editor asks Solomon and George why "nighttime" represents a special separation and vulnerability for the infant. Solomon replies, "The state of the organism is to be more anxious at night" (George, Solomon, \& McIntosh, 2011, p. 524). Richard Bowlby talks about a fear of the night as being part of a baby's genetic code. Some of this could be true, but I am not aware that Bowlby classified periods of sleep of only a few hours as separations, or that serious attachment scholars like Rutter have studied them. Rutter would not have spent time on this issue because it is self-evident that this kind of "loss" is minor and entirely recoverable. John Bowlby did not create a theory to account for overnight sleeps. Bowlby's theory is trivialized by talk about the losses of the Romanian orphans in the same breath as those of American babies who must wait until morning to see mother.

\section{MULTIPLE ATTACHMENTS}

The summary discusses "monotropy," Bowlby's purely theoretical idea that children require a single primary parent to thrive, and, from an ethological standpoint, to survive. The summary states that, "all contributors agreed on the essential role of a primary attachment figure in the first year to two of life" (McIntosh, 2011, p. 422). Certainly, all attachment theorists of note would not agree. Lamb, had he been interviewed, would certainly dissent, having spent a great deal of his time since the 1970s researching the role of both mothers and fathers in the early lives of children.

It does not appear that all of the interviewees agreed either, nor did John Bowlby. Waters pointed out: "The idea that there should be one figure only was not Bowlby's view in the end" (Waters and McIntosh, 2011, p. 480, in reference to Bowlby, 1988, pp. 10-11). Waters goes on to argue that monotropy is not justified by the logic of modern attachment theory, though it is true that infants do better if they are in the care of "one or only a few figures" (p. 480), allowing for at least two primary attachment figures, the mother and the father. Waters argues against the concept of an attachment 
hierarchy, another early idea of Bowlby's, because there is no evidence for the rank-ordering of attachment figures that this implies (with the mother ranked at the top), noting the complementary roles parents usually play for young children.

Siegel also states that a baby can have two primary caregivers, the mother and the father, who have quite different functions. He thought divorce might change things for the family, though he was certain that both men and women were up to the task. Richard Bowlby promotes the idea that there are often two primary attachment figures who serve two complementary and necessary functions, one for "love and security," and the other "to engage in exciting and challenging experiences" (Bowlby \& McIntosh, 2011, p.26). He cites the work of the Grossmann group as formative in this thinking (Grossmann et al., 2002). In her interview, Solomon also notes and supports the findings of the Grossmann group, commenting that these data were consistent with attachment theory and the literature as she understood it.

Klaus and Karin Grossmann conducted two of the substantial long-term outcome studies of attachment, finding few connections overall between early attachment measures and adolescent and adult outcome (Grossmann et al., 2002). They were also among the startlingly small group of attachment researchers who studied the early caregiving of fathers as well as mothers. In their cohort, the quality of the infant's attachment to the mother did predict the child's internal working model of attachment at age ten. The father's sensitivity to his toddler's play predicted attachment status at ten as well. By age 16, however, only the father's early play sensitivity was predictive of adolescent attachment representation (Grossmann et al., 2002). Here and elsewhere, the Grossmann group argues that the secure-base concept, with its emphasis on safety and comfort, varies from a secureexploration concept, which emphasizes companionship, encouragement and the provision of safety as the child learns to explore and delight in his world.

Schore's view of the neurological literature, as described in his interview, also supports the work of the Grossmann group. Schore observed that the father's role is critical to the toddler's competence in the exploration of his world and the development of regulation of aggression in the second year. By the second year of life, "separation from the father will also elicit a stress reaction from the baby, the same as it would with separation from the mother" (Schore \& McIntosh, 2011, p. 505).

None of these points about the role of the father in early development are much elaborated in the interviews, and none are mentioned in the summary. Given that 5 of the 12 interviewees speak very specifically about the important role of fathers in early development, this seems a notable omission. Bretherton (2010) has also recently written at length about the importance of fathers to young children, and of the work of the Grossmanns. A summary statement that mentioned the critical role of fathers in the second year of life would have been helpful, as well as discussion of the necessary developmental unpinning that fathers seem to give their babies. Infant distress at separation from the father would also have borne mention, as a complement to the often-stated concerns about separation from the mother.

\section{PARENTING PLANS AND OVERNIGHTS}

Most of the interviewees declined to offer specific suggestions for parenting plans, many noting the numbers of complex factors that must go into these plans. Most, however, were opposed to all or many overnights with fathers early in life. Only Sroufe offered a specific plan. For fathers of young children, "two short visits during the week and one odd day during the weekend would be plenty" (Sroufe \& McIntosh, p. 468). This statement became the crux of a general quasi-recommendation for parenting plans in the summary: "For babies, visits two to three times per week . . . were thought to be optimal" (McIntosh, 2011, p. 423). This statement is too specific to capture the views of a group that largely stressed the importance of individual factors in deriving parenting plans.

There are practical problems with these kinds of parenting time recommendations for young fathers of divorce, problems more likely encountered by those who regularly attempt to help families and courts derive child-friendly plans. Consider the young father faced with a court order dictating 
short visits during the work week, designed to create a relaxed, if brief, parenting experience while not stressing the baby with undue separations from her mother. He may well have a rigidly scheduled, entry-level job that supports not just himself, but his child and his child's mother. Yet, he must find two, sometimes three, two-hour blocks of parenting time that his employer will allow. His employer will likely have no reason to entertain providing a flexible work schedule to a junior employee. So, the young man leaves work promptly at 5:00 pm, and speeds to the home of his child's mother. He picks up the baby, who may well be cranky because of hunger or fatigue at that time of day. The child may thus struggle against the transition. He then drives at least a few minutes to his home, arriving there just before six. The baby may now be asleep or frantically hungry. The baby's mood does not improve when she is woken, taken out of her car seat, and fed as fast as the father can, but not as fast as the baby wants. By this time, the father may have only half an hour or so to enjoy his child before the drive and transfer to the mother's home begins. It is hard to see anything like this as a child-friendly plan. If the mother works as well, as is often the case, this scenario becomes even more complex. If the parents live more than a few minutes apart, it is impossible.

Overnights are part of the logical solution to this kind of family nightmare. The father (or noncustodial parent) would pick up the baby a night or two during the week at the same time. The baby might still fuss, but once made comfortable, would be at her second home for the night. It would be a familiar place, not a spot where she drops in for the odd visit. The father would bond with the baby over quiet play, bedtime rituals, and nighttime comforting. There would be more time together in the morning. If the baby's mother worked outside the home, transitions might be at the daycare, lessening the child's exposure to conflict. It is hard to see this as a plan that does not benefit the baby.

There are a handful of studies that examine the effect of overnight stays in young children, and all of them are very problematic. Solomon and George (1999a; 1999b) conclude that it is best to limit overnight time, but their studies are significantly flawed, as they state themselves, and as many others have noted (Cashmore \& Parkinson, 2011; Lamb, 2012; Lamb \& Kelly, 2001; Ludolph \& Dale, 2012; Pruett, Cowan, Cowan, \& Diamond, 2012; Warshak, 2000). The McIntosh, Smyth, \& Kelaher (2010) study is also flawed (Cashmore \& Parkinson, 2011; Lamb, 2012; Ludolph \& Dale, 2012; Pruett et al., 2012). Another recent study from the attachment theorists is equally methodologically problematic and, in any case, found that overnights were not harmful to children (Altenhofen, Sutherland, \& Biringen, 2010). Some will say that all studies are imperfect, and all scholars can reject all studies because of this. This research, however, has obvious limitations that give many pause, even Charles Zeanah (Lieberman, Zeanah, \& McIntosh, 2011). All of the studies relied on the mother as the reporter of all or most of the data about the father, with the bias that approach likely entails. The studies collected little or no data on the attachment relationships of fathers and their babies, despite the thirty-year-old literature that infants can form solid attachments to both their fathers and their mothers, and the multiple hypotheses of the studies that would limit infants' time with fathers in divorce. Most studies used inappropriate or nonstandardized measures of attachment and separation. The exception is the careful and well-argued study of Pruett and her colleagues (Pruett et al., 2004), which interviewed fathers as well as mothers and employed standard measures. Also valuable is the pioneering meta-analytic work of Whiteside and Becker (2000).

Since the publication of the July 2011 Special Issue, the guest editor has published a detailed review of all the available studies on overnight care for young children, noting that no parenting plan should be offered "independent of parenting and relationship qualities and psychosocial resources," (McIntosh \& Smyth, 2012, p. 157). She concludes, and I would agree: "The empirical base is embryonic, and further research is needed" (p. 180). Kuehnle and Drozd (2012) edited the impressive volume on empirical approaches to child custody and parenting plans in which the guest editor's 2012 chapter appears. Based on their own substantial knowledge of the field and chapters in their book by experts like Lieberman, McIntosh, Pruett, Kelly, and Lamb, they conclude that there is agreement among developmental psychologists that the overnight issue is far from settled. It is difficult to resolve the guest editor's provision of a quasi-recommendation that significantly limits the time of noncustodial parents in the Special Issue, with her cautions a few months later about the dangers of the provision of exactly such generic parenting plans. 


\section{OVERREACHING THE THEORY AND DATA}

One of the interviewees, Alicia Lieberman, is not only an expert on attachment, but a clinician who works with the children of overburdened and violent families. She appears to have more experience with the courts than most of the interviewees, and is sympathetic to the burdens of the judiciary. Lieberman states a strong opinion succinctly: "Again, and again, I think that theory cannot make law. Theory can guide legal thinking, but no theory accounts for the multiplicity of influences that are enacted in each particular situation" (Lieberman, Zeanah, \& McIntosh, p. 531). Lieberman speaks with wisdom and common sense. Children need individual determinations in divorce, not generic ones based on uncertain theory.

I have presented my views on the ways that the Special Issue, and particularly its summary, overreaches the available research data, doing so by remarkable omissions and over-generalizations. The voluminous literature on the role of fathers in early childhood was barely touched upon. Monotropy was reified, despite its being an idea unsupported by empirical evidence. The serious attention many researchers have given to the attachment capabilities of both parents was virtually unmentioned. Serious losses of childhood were confounded with trivial ones.

The version of attachment theory which the Special Issue seems inclined to make policy is attachment theory in its most traditional form, more traditional at times than the ideas Bowlby held at the end of his life, and certainly different from the current views of scholars like Lamb, Thompson, Rutter, van IJzendoorn, and Dozier. To make attachment theory into policy, or even into law, the Special Issue would have it "trump" the multiple influences to which Lieberman alludes. But many other factors can and do intrude themselves into the custodial equation. As noted aptly throughout the Special Issue, there is conflict and family violence. Again, there is the formative literature on the impact of fathers on their children. Not only do fathers encourage exploration in toddlerhood (Grossmann et al., 2002), but they provide emotional sustenance in different ways than mothers do throughout childhood (Pleck, 2010). They also provide financial support, particularly if they have ample parenting time and become committed to a pattern of adequate child support payments soon after the parental separation (Amato \& Sobolewski, 2004). Attachment theorists themselves, including Sroufe and Waters, have noted the impact of negative life events in later childhood on functioning and attachment status in adolescence and adulthood. This, then, would imply that it would be best if parenting plans were put together to minimize the possibility of childhood trauma and adversity. Numerous other factors are also important, for instance, parental adjustment, community and family support, family income, parental education, and the possibility that a parental relationship might be entirely lost (Kelly, 2012; Ludolph \& Dale, 2012). There certainly is no research that would support a finding that attachment status should necessarily trump all these other influences.

Some questions, of course, have no clear answers in research or in theory. Scholars and clinicians are then well to make clear and careful statements of the limitations of their knowledge. Unfortunately, the tone of the Special Issue was one of more certainty than the literature warrants. Sometimes such thinking does make its way, intentionally or inadvertently, into social policy determinations. It would be a pity if that happened here. Safer by far, and truer to the state of the literature, is a caveat that individual children require individual decision making, whether by their parents or the courts.

\section{NOTE}

I am very grateful for the suggestions and encouragement of Bud Dale, Bill Austin, Judy Cashmore, Leslie Drozd, Robert Emery, Joan Kelly, Michael Lamb, Patrick Parkinson, and Richard Warshak. Their contributions have added much to my thinking and certainly improved this comment.

\section{REFERENCES}

Altenhofen, S., Sutherland, K., \& Biringen, Z. (2010). Families experiencing divorce: Age at onset of overnight stays, conflict, and emotional availability as predictors of child attachment. Journal of Divorce and Remarriage, 51, 141-156. 
Amato, P. R., \& Sobolewski, J. M. (2004). The effects of divorce on fathers and children: Nonresidential fathers and stepfathers. In M. E. Lamb (Ed.), The role of the father in child development (4th ed., pp. 341-367). Hoboken, NJ: Wiley.

Austin, W. G., Ludolph, P. S., \& Gould, J. W. (June, 2011). Relocation, very young children, and child custody evaluation: Forensic issues, research, and ethical considerations. Paper presented at the 48th Annual Conference of the Association of Family and Conciliation Courts, Orlando, FL.

Bowlby, J. (1951). Maternal care and mental health (World Health Organization Monograph Series No. 2). Geneva, Switzerland: World Health Organization.

Bowlby, J. (1973). Attachment and loss: Separation (Vol. 2). New York: Basic Books.

Bowlby, J. (1980). Attachment and loss: Loss (Vol. 3). New York: Basic Books.

Bowlby, J. (1988). A secure base: Parent-child attachment and healthy human development. New York: Basic Books.

Bowlby, R., \& McIntosh, J. (2011). John Bowlby's legacy and meanings for the family law field: In conversation with Sir Richard Bowlby. Family Court Review, 49, 549-556.

Bretherton, I. (2010). Fathers in attachment theory and research: A review. Early Child Development and Care, 180(1\&2), 9-23.

Cashmore, J., \& Parkinson, P. (2011). Parenting arrangements for young children: Messages from research. Australian Journal of Family Law, 25(3), 236-257.

George, C., Solomon, J., \& McIntosh, J. (2011). Divorce in the nursery: On infants and overnight care. Family Court Review, $49,521-528$.

Grossmann, K., Grossmann, K. E., Fremmer-Bombik, E., Kinder, H., Scheuerer-Englisch, H., \& Zimmermann, P. (2002). The uniqueness of the child-father attachment relationship: Fathers' sensitive and challenging play as a pivotal variable in a 16-year longitudinal study. Social Development, 11, 307-331.

Kelly, J. B. (2012). Risk and protective factors associated with child and adolescent adjustment following separation and divorce: Social science applications. In K. Kuehnle \& L. Drozd (Eds.), Parenting plan evaluations: Applied research for the family court (pp. 49-84). New York: Oxford University Press.

Kelly, J. B., \& Lamb, M. E. (2000). Using child development research to make appropriate custody and access decisions for young children. Family and Conciliation Courts Review, 38, 297-311.

Kuehnle, K. F., \& Drozd, L. M. (2012). Evidence-based practice. In K. Kuehnle, \& L. Drozd (Eds.), Parenting plan evaluations: Applied research for the family court (pp. 577-582). New York: Oxford University Press.

Lamb, M. E. (2012). Critical analysis of research on parenting plans and children's well-being. In K. Kuehnle \& L. Drozd (Eds.), Parenting plan evaluations: Applied research for the family court (pp. 214-243). New York: Oxford University Press.

Lamb, M. E., \& Kelly, J. B. (2001). Using the empirical literature to guide the development of parenting plans for young children: A rejoinder to Solomon and Biringen. Family Court Review, 39, 365-371.

Lieberman, A., Zeanah, C., \& McIntosh, J. (2011). Attachment perspectives on domestic violence and family law. Family Court Review, 49, 529-538.

Ludolph, P. S., \& Dale, M. D. (2012). Attachment in child custody: An additive factor, not a determinative one. Family Law Quarterly, 46(1).

Main, M., Hesse, E., \& Hesse, S. (2011). Attachment theory and research: Overview with suggested applications to child custody. Family Court Review, 49, 426-463.

McIntosh, J. E. (2011). Guest editor's introduction to special issue on attachment theory, separation, and divorce: Forging coherent understandings for family law. Family Court Review, 49, 418-425.

McIntosh, J. E., \& Smyth, B. (2012). Shared-time parenting: An evidence-based matrix for evaluating risk. In K. Kuehnle \& L. Drozd (Eds.), Parenting plan evaluations: Applied research for the family court (pp. 155-187). New York: Oxford University Press.

McIntosh, J. E., Smyth, B., \& Kelaher, M. (2010). Overnight care patterns and psycho-emotional development in infants and young children. In J. McIntosh, B. Smyth, M. Kelaher, Y. Wells, \& C. Long (Eds.), Post-separation parenting arrangements and developmental outcomes for children: Collected reports; Report to the Australian Government Attorney-General's department: Canberra (pp. 85-168). Victoria, Australia: Family Transitions.

Pleck, J. H. (2010). Paternal involvement: Revised conceptualization and theoretical linkages with child outcomes. In M.E. Lamb (Ed.), The role of the father in child development (5th ed., pp. 58-93). Hoboken, NJ: Wiley.

Pruett, M. K., Cowan, C. P., Cowan, P. A., \& Diamond, J. S. (2012). Supporting father involvement in the context of separation and divorce. In K. Kuehnle \& L. Drozd (Eds.), Parenting plan evaluations: Applied research for the family court (pp. 123-151). New York: Oxford University Press.

Pruett, M. K., Ebling, R., \&, Insabella, G. (2004). Critical aspects of parenting plans for young children: Interjecting data into the debate about overnights. Family Court Review, 42, 39-59.

Robertson, J., \& Robertson, J. (1971). Young children in brief separation: A fresh look. Psychoanalytic Study of the Child, 26, 264-315.

Rutter, M. (1971). Parent-child separation: Psychological effects on the children. Journal of Child Psychology and Psychiatry, 12, 233-260.

Rutter, M., \& Sonuga-Barke, E. J. (2010). X. Conclusions: Overview of findings from the ERA Study, inferences, and research implications. Monographs of the Society for Research in Child Development, 75, 212-229. 
Sagi, A., Koren-Karie, N., Gini, M., Ziv, Y., \& Joels, T. (2002). Shedding further light on the effects of various types and quality of arly child care on infant-mother attachment relationship: The Haifa Study of Early Child Care. Child Development, 73, 1166-1186.

Schore, A. \& McIntosh, J. (2011). Family law and the neuroscience of attachment, part I. Family Court Review, 49, 501-512.

Siegel, D., \& McIntosh, J. (2011). Family law and the neuroscience of attachment, part II. Family Court Review, 49, 513-520.

Solomon, J., \& George, C. (1999a). The development of attachment in separated and divorced families: Effects of overnight visitation, parent and couple variables. Attachment and Human Development, 1(1), 2-33.

Solomon, J., \& George, C. (1999b). The effects on attachment of overnight visitation in divorced and separated families: A longitudinal follow-up. In J. Solomon \& C. George (Eds.), Attachment disorganization (pp. 243-264). New York: Guilford.

Sroufe, L. A. (2005). Attachment and development: A prospective, longitudinal study from birth to adulthood. Attachment and Human Development, 7, 349-367.

Sroufe, L. A., Egelund, B., Carlson, E. A., \& Collins, W. A. (2005). The development of the person: The Minnesota Study of Risk and Adaptation from Birth to Adulthood. New York: Guilford.

Sroufe, A., \& McIntosh, J. (2011). Divorce and attachment relationships: The longitudinal journey. Family Court Review, 49, 464-473.

Thompson, R. A. (2006). The development of the person: Social understanding, relationships, self, conscience. In W. Damon \& R. M. Lerner (Series Eds.) \& N. Eisenberg (Vol. Ed.), Handbook of child psychology: Vol. 3. Social, emotional, and personality development (6th ed., pp. 24-98). Hoboken, NJ: Wiley.

Warshak, R. A. (2000). Blanket restrictions: Overnight contact between parents and young children. Family and Conciliation Courts Review, 38, 422-445.

Waters, E., \& McIntosh, J. (2011). Are we asking the right questions about attachment? Family Court Review, 49, 474-482.

Waters, E., Merrick, S. Treboux, D., Crowell, J., \& Albersheim, L. (2000). Attachment security in infancy and early adulthood: A twenty-year longitudinal study. Child Development, 71, 684-689.

Whiteside, M. F., \& Becker, B. J. (2000). Parental factors and the young child's postdivorce adjustment: A meta-analysis with implications for parenting arrangements. Journal of Family Psychology, 14(1), 5-26.

Zeanah, C. H., \& Smyke, A. T. (2008). Attachment disorders in family and social context. Infant Mental Health Journal, 29, 219-233.

Zeanah, C. H., Smyke, A. T., Koga, S. F., \& Carlson, E. (2005). Attachment in institutionalized and community children in Romania. Child Development, 76, 1015-1028.

Pamela Ludolph is a clinical and forensic psychologist in Ann Arbor, Michigan, and a lecturer at the University of Michigan. She holds an AB in psychology from Mount Holyoke College, an AM in educational theory from the University of Toronto, and an MA and PhD in clinical psychology from the University of Michigan. She often is asked to conduct child custody and access evaluations for the courts, as well as court-ordered treatment of families troubled by highly conflicted divorce and allegations of child maltreatment. Her professional and research interests involve attachment, alienation, relocation, and assessment, particularly in families with very young children. 